\title{
Dysphagia Due to Inflammation of Oral Muscles as the First Symptom of Dermatomyositis
}

Goh Otao, Shu-ichi Yamashita, Itaru Kyoraku, Kazutaka Shiomi and Masamitsu Nakazato

Key words: inflammation of oral muscles, fat-saturated image of MRI

(DOI: 10.2169/internalmedicine.46.0068)
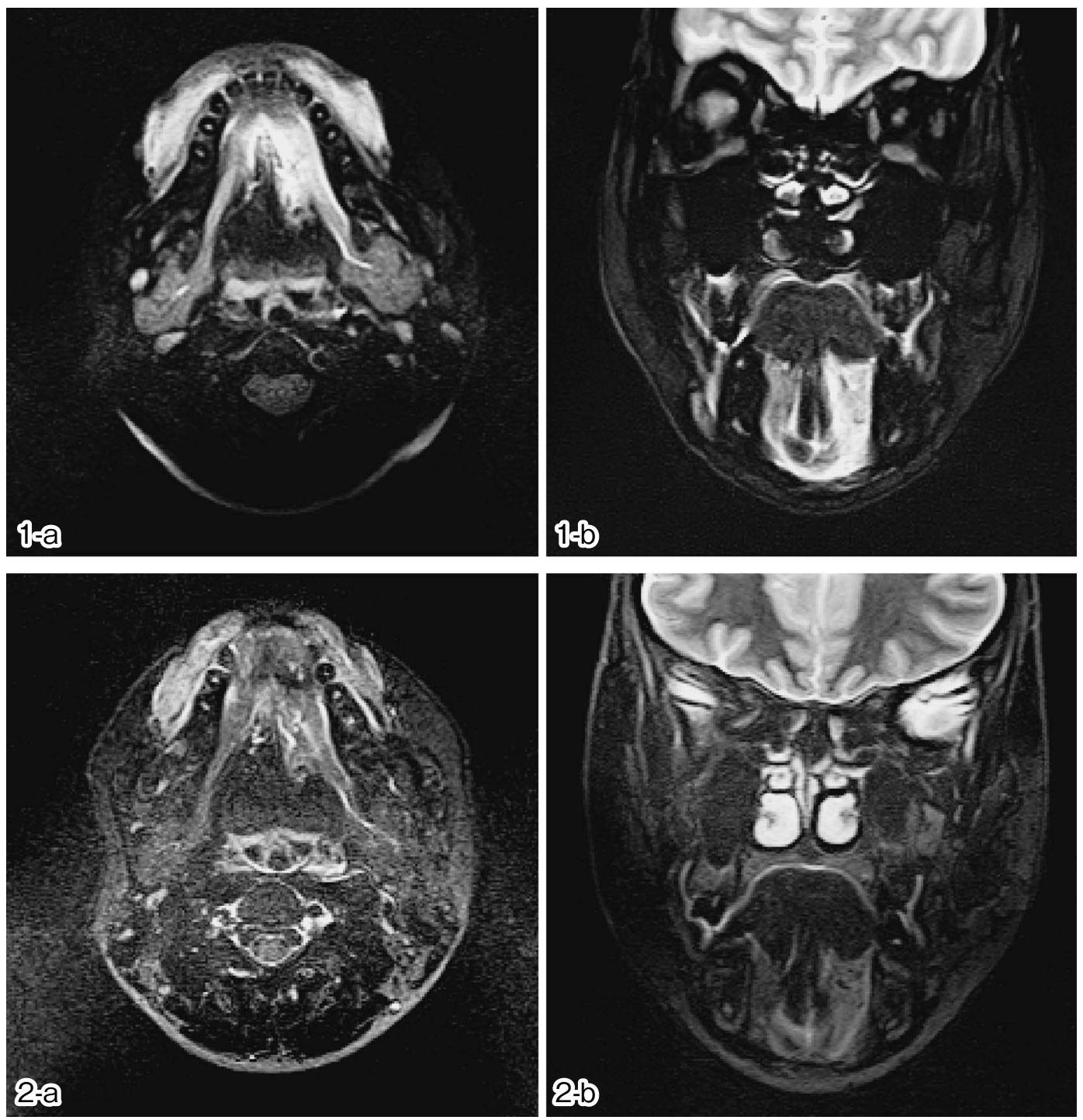

Picture 1. T2-weighted fat-saturated images of MRI showed the high intensity lesions in the subglossal and submandiblar spaces including mylohyoid and geniohyoid muscle. The change is more conspicuous in the left side. Horizontal (a) and coronal (b) images.

Picture 2. The high intensity lesion of MRI improved markedly with steroid therapy. Horizontal (a) and coronal (b) images.

Neurology, Respirology, Endocrinology and Metabolism, Internal Medicine, Faculty of Medicine, University of Miyazaki, Miyazaki Received for publication January 31, 2007; Accepted for publication February 19, 2007

Correspondence to Dr. Shu-ichi Yamashita, syama@miyazaki-catv.ne.jp 
A 30-year-old woman started to have difficulty in swallowing two months before her admission to our hospital. She also had submandibular pain. She gradually developed weakness in her proximal arms and legs and lilac-colored maculopapular eruption in her cheeks, forehead and neck. On admission, muscle strength on the Medical Research Council scale was grade 3 in the neck flexors, 3 in the proximal arms and 4 in the legs. Although she had painful swelling in her oral floor, the movement of her pharynges and the power of the tongue were intact. Serum creatine kinase $(\mathrm{CK})$ was $2,867 \mathrm{U} / \mathrm{L}$. Inflammatory changes in the muscles of oral floor (Pictures 1a, 1b), arms and legs were detected with the T2-weighted fat-saturated images of magnetic resonance imaging (MRI). Biopsy finding of left biceps muscle showed the infiltration of T-cell phenotype lym- phocytes mainly in the perivascular areas, and that of neck skin also showed infiltration of lymphocytes and plasma cells in the perivascular and adnexal spaces in the upper dermis. A diagnosis of dermatomyositis was made. Intravenous methylprednisolone administration was started at a daily dose of $1,000 \mathrm{mg}$ for three days followed by $60 \mathrm{mg}$ of oral prednisolone. Her clinical condition, including dysphagia and submandibular pain, was gradually ameliorated with the therapy and the serum CK level decreased to normal range. Inflammatory findings of MRI in the muscles of oral floor markedly improved (Pictures 2a, 2b). This is the first report of oral muscle inflammation confirmed by MRI, though three similar cases have been reported without MRI findings (1-3).

\section{References}

1. Brown TF, Carr MM, Covert AA, et al. Focal myositis in the mylohyoid muscle of an adult. J Otolaryngol 29: 47-50, 2000.

2. McCluggage WG, Mirakhur M. Focal myositis of the floor of mouth: report of two cases and review of the literature. Oral Surg
Oral Med Oral Pathol Oral Radiol Endod 81: 573-575, 1996.

3. Choi SS, Myer CM 3rd. Proliferative myositis of the mylohyoid muscle. Am J Otolaryngol 11: 198-202, 1990.

(C) 2007 The Japanese Society of Internal Medicine http://www.naika.or.jp/imindex.html 